\title{
A systematic review of studies describing the influence of informal social support on psychological wellbeing in people bereaved by sudden or violent causes of death
}

\author{
H. R. Scott ${ }^{*}$ (D, A. Pitman ${ }^{1}$, P. Kozhuharova ${ }^{2}$ and B. Lloyd-Evans ${ }^{1}$
}

\begin{abstract}
Background: Whilst any type of bereavement can be traumatic, bereavement through violent or sudden causes is associated with more severe negative health and wellbeing outcomes compared to other types of loss. Social support has been found to have a positive impact on wellbeing after traumatic events in general. However, this association appears to be less consistently demonstrated in studies that focus on bereavement, and the literature in this area has not yet been systematically reviewed. This study aimed to review the international literature to examine systematically whether there is an association between informal social support from family and friends after bereavement through sudden and/or violent causes and post-bereavement wellbeing.

Methods: We conducted a systematic search for quantitative studies that tested for an association between social support and any outcome related to wellbeing after a sudden and/or violent loss. Included studies were assessed for quality, and findings were reported using the approach of narrative synthesis. The review was pre-registered on Prospero (registration number CRD42018093704).

Results: We identified 16 papers that met inclusion criteria, 11 of which we assessed as being of good or fair quality and 5 as poor quality. Fifteen different wellbeing outcomes were measured across all studies. We found consistent evidence for an inverse association between social support and symptoms/presence of depression, predominantly consistent evidence for an inverse association between social support and symptoms/presence of post-traumatic stress disorder (PTSD), and conflicting evidence for an inverse association between social support and symptoms/presence of complicated grief.

(Continued on next page)
\end{abstract}

\footnotetext{
* Correspondence: Hannah.scott.17@ucl.ac.uk

'Division of Psychiatry, University College London, 6th floor, Maple House, 149 Tottenham Court Road, London W1T 7BN, UK

Full list of author information is available at the end of the article
}

C C The Author(s). 2020 Open Access This article is licensed under a Creative Commons Attribution 4.0 International License, which permits use, sharing, adaptation, distribution and reproduction in any medium or format, as long as you give appropriate credit to the original author(s) and the source, provide a link to the Creative Commons licence, and indicate if changes were made. The images or other third party material in this article are included in the article's Creative Commons licence, unless indicated otherwise in a credit line to the material. If material is not included in the article's Creative Commons licence and your intended use is not permitted by statutory regulation or exceeds the permitted use, you will need to obtain permission directly from the copyright holder. To view a copy of this licence, visit http://creativecommons.org/licenses/by/4.0/ The Creative Commons Public Domain Dedication waiver (http://creativecommons.org/publicdomain/zero/1.0/) applies to the data made available in this article, unless otherwise stated in a credit line to the data. 


\begin{abstract}
(Continued from previous page)
Conclusions: Our systematic review identified evidence to suggest that social support after sudden or violent bereavement is associated with a reduced severity of depressive and PTSD symptoms. Further longitudinal research is needed to explore potential causality in this relationship, widening the focus from common mental disorders to include other mental illnesses, wellbeing outcomes, and suicide-related outcomes after bereavement. There is also a need for consensus on the conceptualisation and measurement of social support. Our findings imply that interventions to improve access to and quality of social support may reduce the burden of mental illness after bereavement, and may therefore be worth investing in.
\end{abstract}

Keywords: Bereavement, Violent loss, Sudden loss, Social support

\section{Background}

Bereavement is a stressful life event that can have a long-lasting negative impact on wellbeing and quality of life [1]. All types of bereavement present a significant challenge in terms of adapting to life without the deceased. According to the dual process model [2], adapting to a loss requires dealing with both loss and restoration oriented stressors; dealing with the changes and feelings that relate to the death itself as well as the changes in roles and responsibilities it brings.

This model is compatible with the idea that certain types of loss are more challenging to adapt to than others [3]. Losses that are sudden (such as those arising from natural disasters, transport accidents) do not allow those left behind the chance to prepare: either for the loss of their relationship with the deceased or for any additional role they may take on, such as financial or caregiving duties. Violent losses (such as homicide or suicide) are also generally sudden, but are additionally challenging in terms of loss-oriented stressors as they violate the assumption that human life must be protected [4]. A systematic review [5] found consistent evidential support that losses that are both sudden and violent are distinct from other form of loss, being associated with slower recovery and an increased risk or prevalence of mental health disorders such as PTSD and depression compared to bereavement from natural deaths.

Social support has been proposed as protective against the negative effects of stressful life events [6]. Whilst the definition and conceptualisation of social support in research varies [7], informal social support describes the help provided by the individual's existing social network, whereas formal social support describes organised help from individuals who may be professionals (such as trained peer group facilitators) or non-professionals (such as peer group members) [8]. There are two models through which this effect is proposed to work; the main effects model and the buffering model. The buffering model [9] suggests that social support has a protective effect on the negative impact of stressful life events by moderating the relationship between stress and wellbeing, rather than an overall positive effect on individuals regardless of their situation, as proposed in the main effects model [10]. In the wider literature, there is support for both models, but more consistent evidence for social support having an overall impact on wellbeing irrespective of levels of stress $[11,12]$. The main effects model also takes into account the potential positive benefits of social support beyond negating stressors [13]. In particular, better social support is associated with a lower level of depressive and PTSD symptoms $[6,14]$.

There is limited empirical support for the effectiveness of formal social support interventions following sudden and violent loss [4], findings mirrored by evidence regarding those who have experience any kind of loss [15]. The same is true for more specific groups, such as those bereaved by suicide, where a recent systematic review has found that a diverse range of different interventions have been assessed for effectiveness using a range of outcomes measures, leading to inconclusive evidence for best practice [16]. Interventions based on peer support services, where individuals use shared experience to support one another, have a more consistent positive benefit [17]. However, formal sources of social support, including as peer support, must be sought out proactively. Research, however, shows that those bereaved by sudden causes are more likely to access informal social support [18], described as the provision of help from other people, typically emotional, tangible, informational and companionship support [19]. Informal social support is therefore the most accessable and personalisable type of support available to those bereaved through violent and/ or sudden causes [20]: interventions to improve access to informal social support for people in this situation could therefore be valuable if its relationship to higher levels of wellbeing is established in this context.

The most recent review of the impact of informal social support on wellbeing outcomes after bereavement was carried out 14 years ago [21]. However, this was a non-systematic review that focussed on studies with a primary aim of testing the buffering hypothesis of social support but instead finding support for the main effects model. The eight included studies found mixed evidence 
to support social support after bereavement as having a significant impact on wellbeing. Given the specific nature of the inclusion criteria for interventions in that review, it is likely that a number of relevant papers examining the impact of social support after a loss were not included. Additionally, the mixed findings could be explained by the inclusion of heterogeneous samples bereaved by all types of loss.

To address an identified gap in current knowledge, our review sought to understand whether informal social support is associated with wellbeing after a loss through sudden and/or violent causes, by synthesising evidence from studies that compared measures of psychological wellbeing in those who received varying levels of informal support after bereavement.

\section{Methods}

\section{Study inclusion}

We included peer-reviewed primary observational (cross-sectional or longitudinal) research studies published as a full paper rather than solely an abstract, which used quantitative methods to investigate the association between social support and wellbeing of adults (18 years old or over) following bereavement through violent and/or sudden death. Violent deaths were defined as those that were unnatural and caused by human action [22], whereas sudden deaths were those that were unexpected and occurred instantly or rapidly [23]. It was a requirement that study participants identified as having had a personal relationship (friend or family member) with the deceased.

Exposure was defined as participants' first-hand experience of any form of social support, provided by family or friends outside a formal setting (i.e. excluding peer mentoring groups or care-giving agencies) after their loss. We only included studies in which social support measures had been psychometrically validated regarding one or more of: content, criterion or construct validity. We included studies that assessed the outcomes of: i) psychological wellbeing, defined as positive psychological adjustment, measured using validated indicators of psychological adjustment (such as measures of social involvement, life satisfaction or sense of purpose); or ii) psychiatric symptoms (such as a clinical diagnosis of a mental health problem or a measure of mental health symptom severity assessed using a psychometrically validated assessment tool); or iii) a measure of service use in relation to mental health problems.

Our exclusion criteria were: studies that solely analysed data qualitatively or did not specify cause of death.

\section{Study selection}

We registered the protocol for this review with PROSPERO: registration number CRD42018093704. Our search terms combined terms for: sudden or violent bereavement; and informal social support; and mental health or wellbeing (Additional file 1: Appendix 1). The protocol was reviewed by our Public and Patient Involvement (PPI) representatives who confirmed that the review question was of value and commented on the search terms, and also by a university librarian (see Acknowledgements).

We conducted a systematic search of five online databases: IBSS, CINAHL, PsychINFO, MEDLINE and the Cochrane library. Our inclusion criteria were observational studies published from database inception up to 26th April 2018 without language or date limits. The search was updated a year later, with records searched up to 10th May 2019.

In addition to the database searches, we handsearched from journal inception three relevant journals, Bereavement Care, Death Studies and OMEGA- The Journal of Death and Dying. We also hand-searched conference abstracts from all available online records of key relevant conferences (International Death, Grief and Bereavement conference; European Symposium on Suicide and Suicidal Behaviour) as well as grey literature sources (OpenGrey, OpenDOAR, EThOS and OATD databases searched). For each study identified for inclusion in the review, we hand-searched the reference list and used forward citation tracking. We extracted and managed references using Endnote software.

For 29 studies that reported they had recorded death type but not distinguished between types of death in statistical analyses, authors were contacted to request further information.

To screen references we followed the Preferred Reporting Items for Systematic Reviews and MetaAnalyses (PRISMA) guidelines ([24]; checklist included as Additional file 1: appendix 2). The first author reviewed all titles, identifying abstracts for review, and thereby full text articles for review. A second author (PK) independently reviewed $15 \%$ of article abstracts and full text articles, with any disagreements discussed between authors.

\section{Data extraction}

We developed a standardised schedule to extract data (attached as Additional file 1: appendix 3) and summarise details of the study setting, sample, measures of intervention and outcome and results. The second author independently extracted data from $15 \%$ of the included papers, with any disagreements discussed between authors.

\section{Quality appraisal}

Following data extraction, we used the NewcastleOttawa Scale for evaluating the quality of non- 
randomised studies [NOS; [22]] to assess the quality of the included longitudinal studies three domains: selection, comparability and outcome. Discounting the criteria covering the selection of a non-exposed cohort that would not be applicable to single-group studies, a maximum score of 8 was possible. As the NOS has been designed primarily for cohort and case control studies, an adapted version of the NOS [25] was used to assess the quality of the included cross-sectional studies. A maximum score of 10 was possible for this scale.

The first and second reviewing authors independently reviewed each of the included studies according to the criteria set out in the tool, and where disagreements arose over assessment of bias, these were discussed with other authors.

We interpreted scores according to the rating system used for the standard NOS. To be rated as being good quality, studies had to score 3 or 4 points in the selection domain, 1 or 2 points in the comparability domain and 2 or 3 points in the outcome/exposure domain. For fair quality, studies had to score 2 points in selection domain, 1 or 2 points in the comparability domain and 2 or 3 points in the outcome/exposure domain. Studies were deemed to be poor quality if they scored 0 or 1 point in the selection domain, 0 points in comparability domain or 0 or 1 points in the outcome/exposure domain.

\section{Analysis}

As we expected that included studies would be heterogeneous in terms of conceptualisations of social support, study settings, participant characteristics and the measures and statistical analyses used, we did not anticipate conducting a meta-analysis but instead planned to use the approach of narrative synthesis, grouping findings by outcome. For this we referred to an existing framework [26] to ensure a systematic approach. This framework starts by developing a theory of how the exposure works, why and for whom, before developing a preliminary synthesis of findings, exploring relationships in the data, and assessing robustness of the synthesis. When discussing study results, we used "positive association" if all measured social support variables had a significant positive association with the reduced severity of, or reduced likelihood for meeting the threshold of diagnosis for a measured outcome. We used "partial positive association" if some but not all of the included social support variables had a significant positive association with reduced severity of, or reduced likelihood for meeting the threshold of diagnosis for the measured outcome, and the remaining included variables were not significantly associated with the outcome.

It was planned that results would initially be grouped by outcome, with specific sub-group analysis based on type of loss or social support measurement reported where appropriate.

\section{Results \\ Included studies}

Using electronic database searches we identified 6556 records for title and abstract screening after removing duplicates (Fig. 1). We conducted a full text review of 263 records, of which 16 met all the inclusion criteria and were included in the narrative synthesis. Foreign language full text articles were translated (seven in Japanese, two in Spanish, two in German, two in Chinese (simplified) and one in French). No additional studies were found through grey literature searching, or hand searches of journal contents of included studies' reference lists.

Initial rates of agreement between the two reviewing authors were $97 \%$ for screening, $98 \%$ for data extraction and $98 \%$ for the quality assessment. All disagreements were resolved through discussion.

\section{Study characteristics}

The 16 included papers reported results from 15 different studies, with one study reported in two included papers $[27,28]$ at different follow-up time points.

Of the 15 samples included (Table 1), nine sampled populations in North America (USA and Canada) [27$29,31,33,45,47,48,50]$, two in China $[44,52]$ two in Israel [41, 42], one in Colombia [38] and one in Norway [40]. The earliest study was published in 1985 and the most recent in 2019. The sample size of included studies ranged between 44 and 803 participants. Mean age of samples ranged between 33 and 79 and, except for one study, the majority of participants in each sample were female. Participant groups were defined as those bereaved by natural disasters $[27,40,44,52,54]$, homicide $[29,31,33,47]$, suicide [42, 43, 45, 48], accidental death $[36,50]$ or armed conflict [38]. One study was longitudinal in design [26], and measured outcomes 6 months after baseline measurement (at a mean of 1.66 years post-loss). Another study [55] followed-up a sample described in an included cross-sectional analysis [27] but reported different measures, so was essentially a separate cross-sectional analysis and not comparable. All other studies were cross-sectional in design.

Across the 15 different studies, 11 different validated measures of social support were used (Table 2). The Multidimensional Scale of Perceived Social Support (MSPSS) [57] was the most frequently included measure, employed in five studies [29, 33, 42-44].

Measures were based on different theoretical approaches to social support, with some distinguishing between perceived and received social support (measuring one or both), and some distinguishing between 


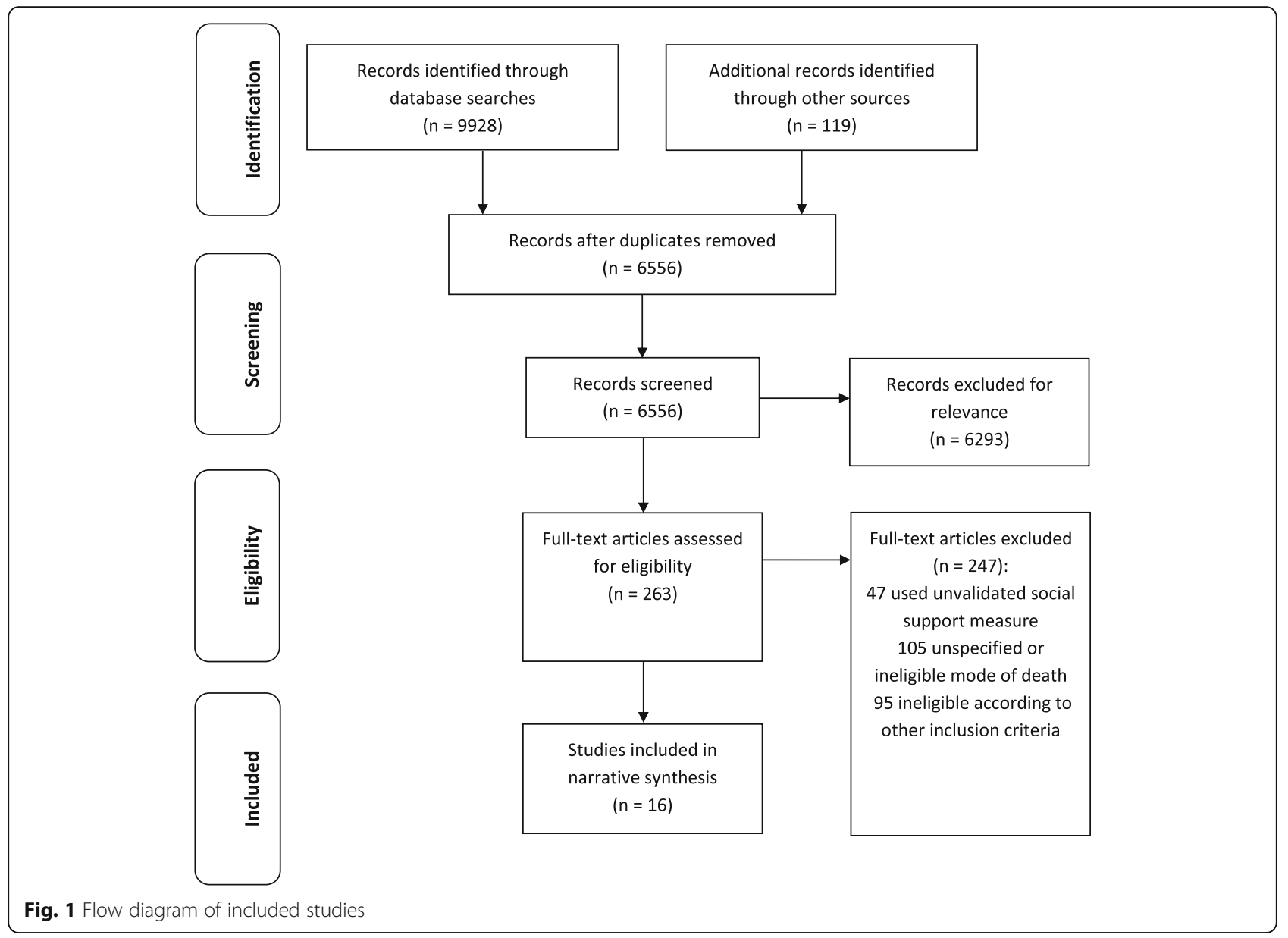

structural support (integration with social network) and functional support (specific functions provided by others) and measuring one or both [59], and some developed and validated for specific populations.

Across the 15 different studies, 15 different mental health and psychological wellbeing outcomes were measured. The most frequently measured outcomes were post-traumatic stress disorder [31, 33, 38, 47, 50, 52], depression [27, 31, 33, 36, 45, 47, 48] and complicated grief $[31,33,40,43,47]$. The remaining measures were of other distinct psychiatric and psychological wellbeing outcomes (Table 3). No studies measured service use as an indicator of wellbeing. Where studies measured prevalence of an outcome rather than symptom severity, a cut-off score on an assessment tool was used rather than self-report of an existing clinical diagnosis.

\section{Quality assessments}

Table 4 shows the results of the NOS quality assessments for included studies. Most studies were judged as either good quality $[40,43,45,47,50,52]$ or fair quality [27, 28, $31,36,38]$, and five studies were rated as poor quality [29, $33,42,44,48]$. The most frequent source of bias was sample size. No studies were deemed to have a justified sample size as none had carried out a power calculation. Low response rate or no response rate, and lack of comparison between respondents and non-respondents were also a common source of bias across studies, where 13 studies did not meet the criteria to score a point in this category.

In addition to the NOS, we noted that exploratory approaches were common, with multiple statistical models often used in study analyses, reflecting multiple outcomes and exposure variables. There was also great variation in the degree to which analyses controlled for potential confounding variables, and in the specific variables chosen as potential confounders, resulting in a risk of residual confounding in reported estimates.

\section{Summary of findings}

Table 5 summarises the overall findings extracted from included studies for each outcome type.

\section{Psychiatric outcomes}

Depression (seven studies) There was limited evidence that social support was associated with reduced risk of 


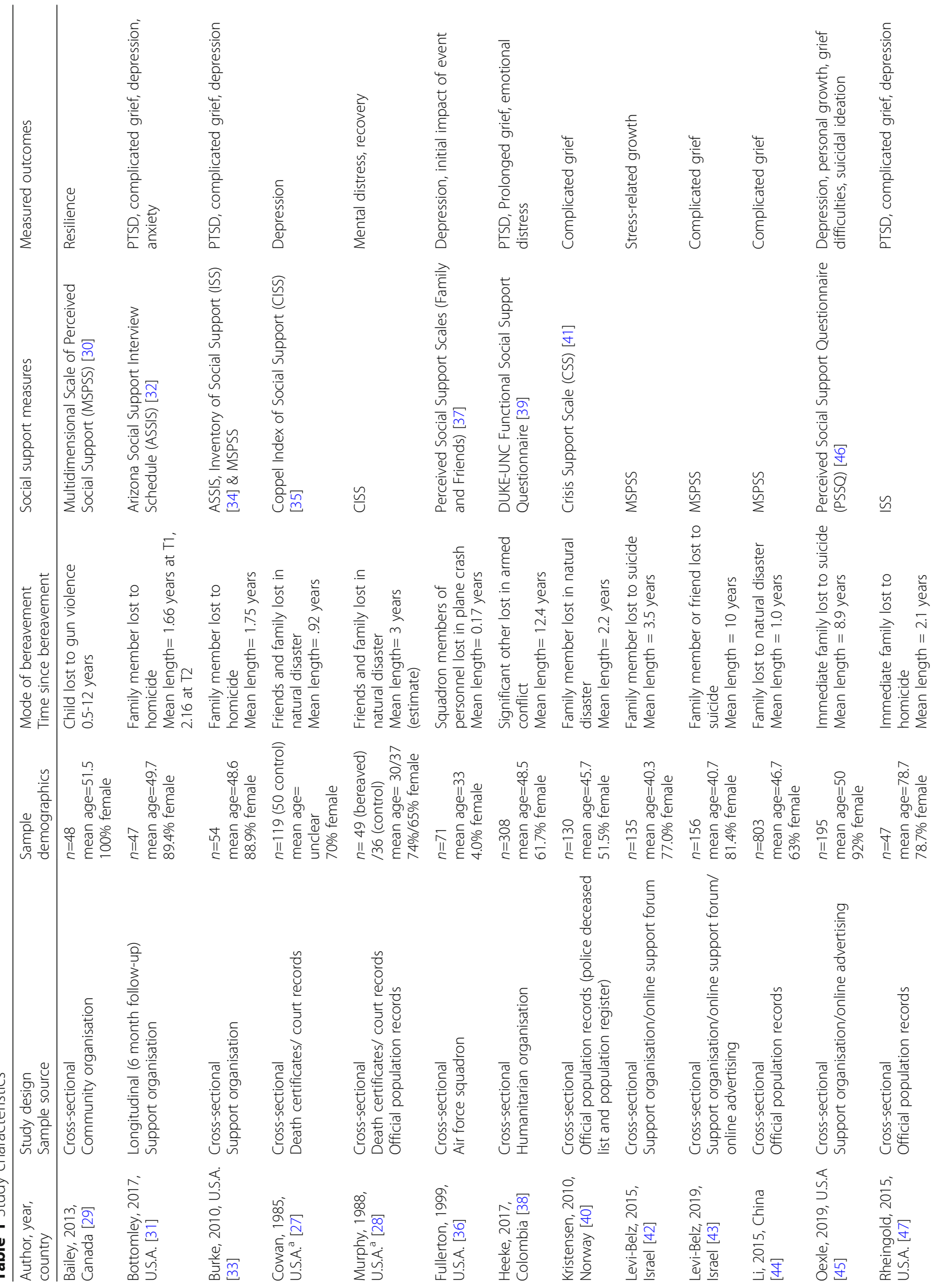




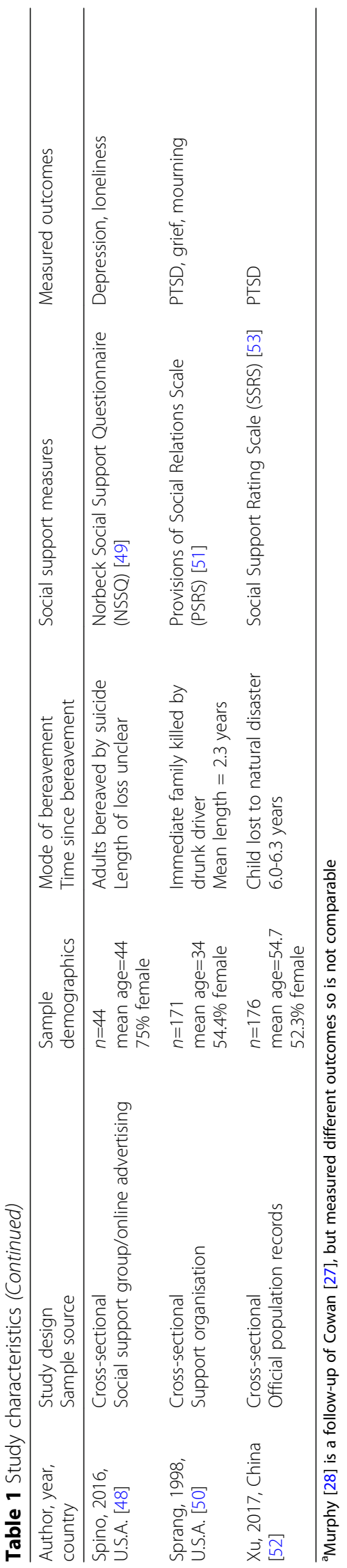




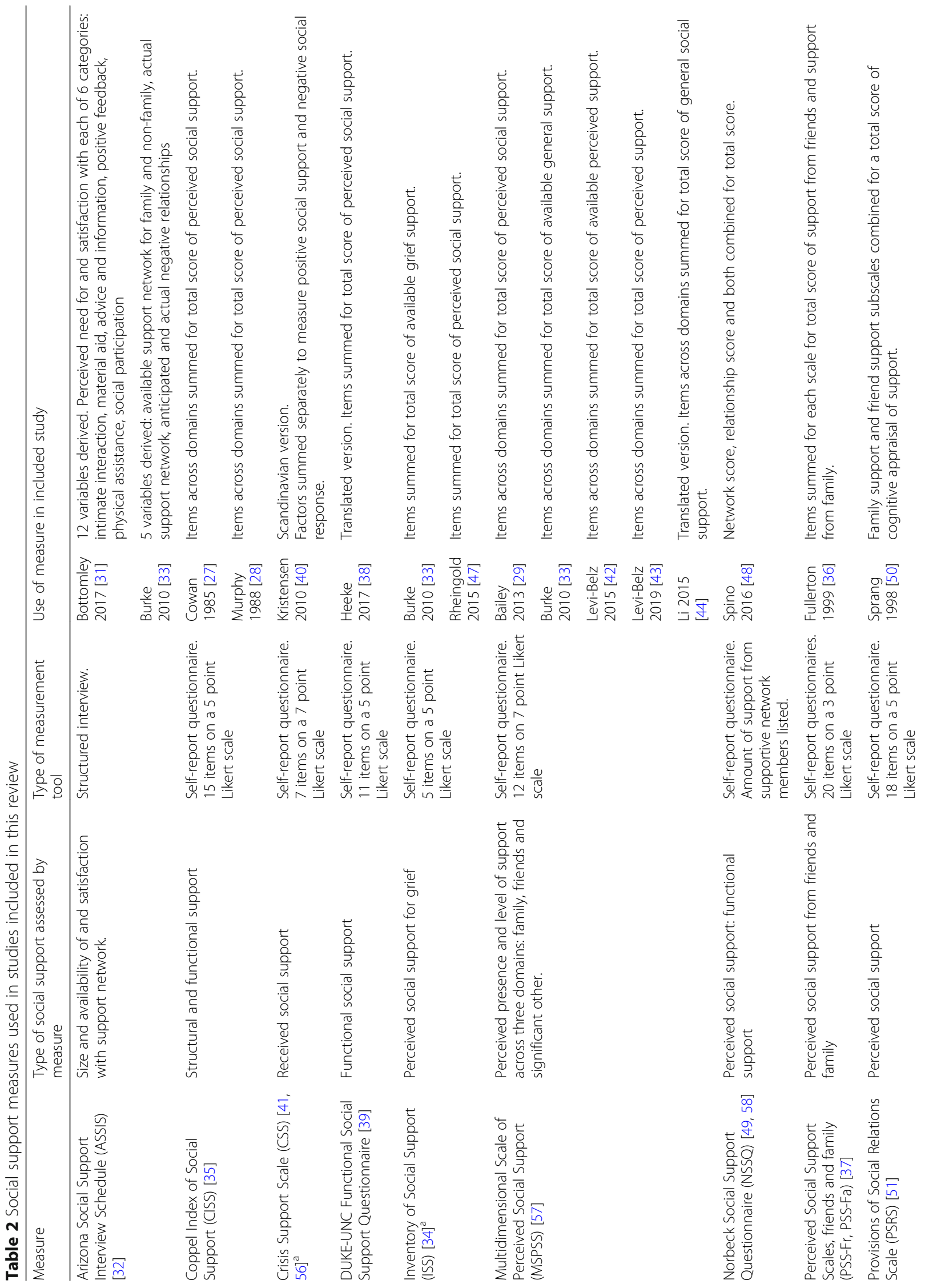




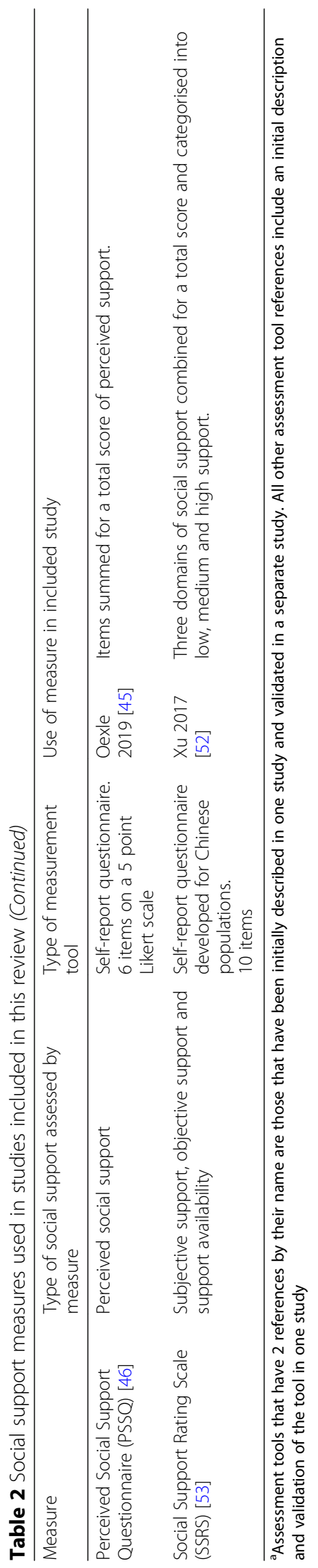




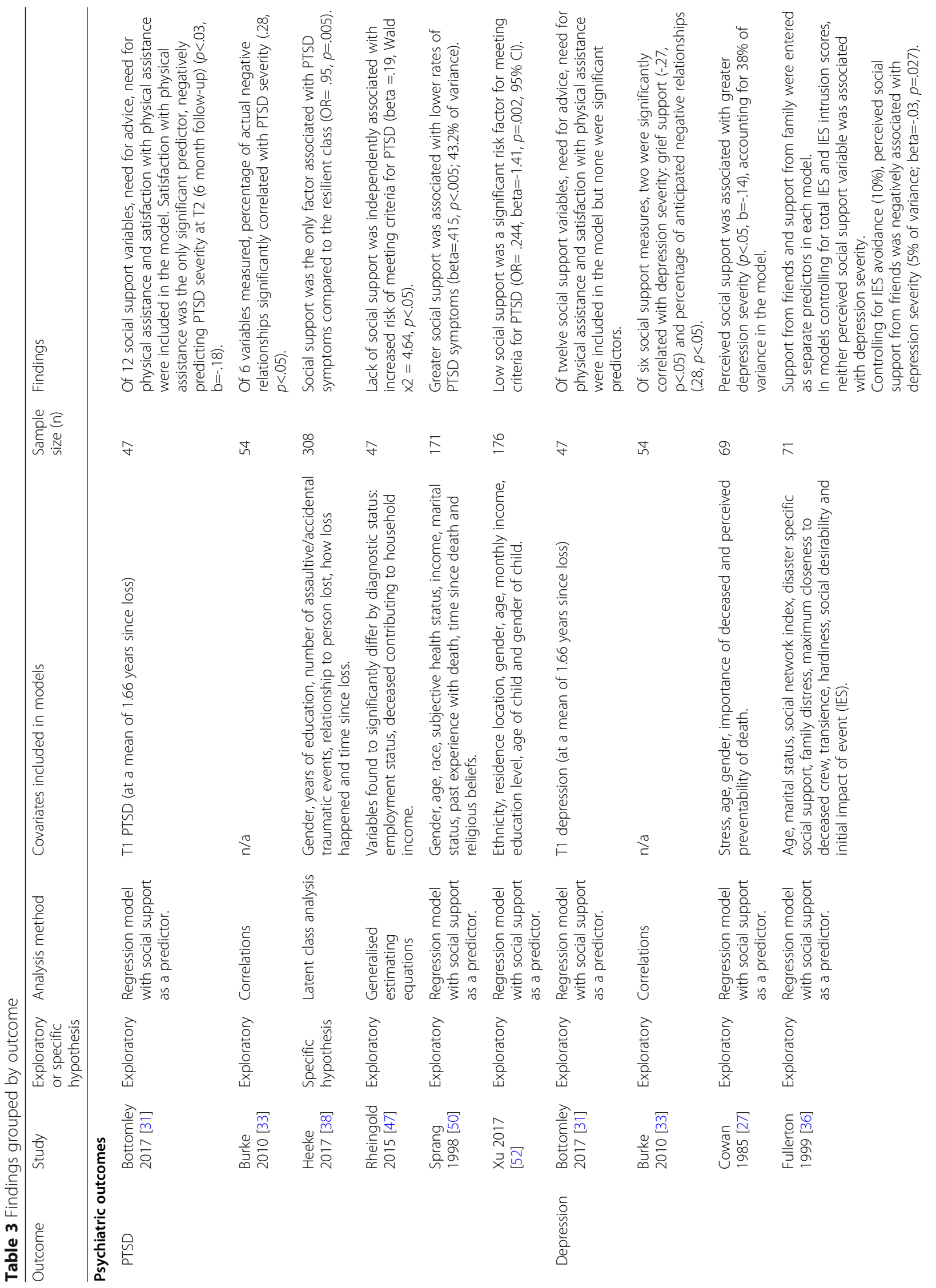




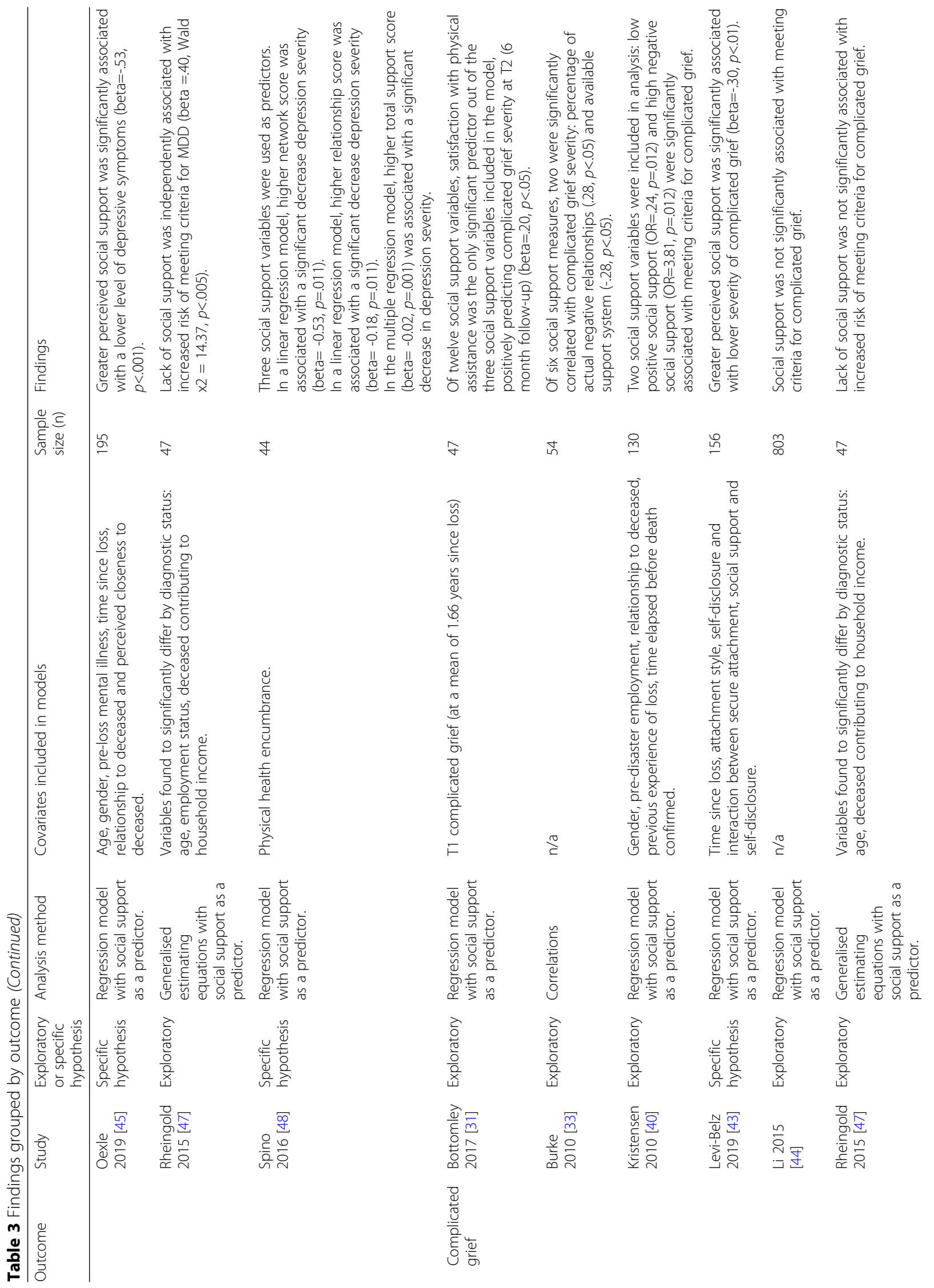




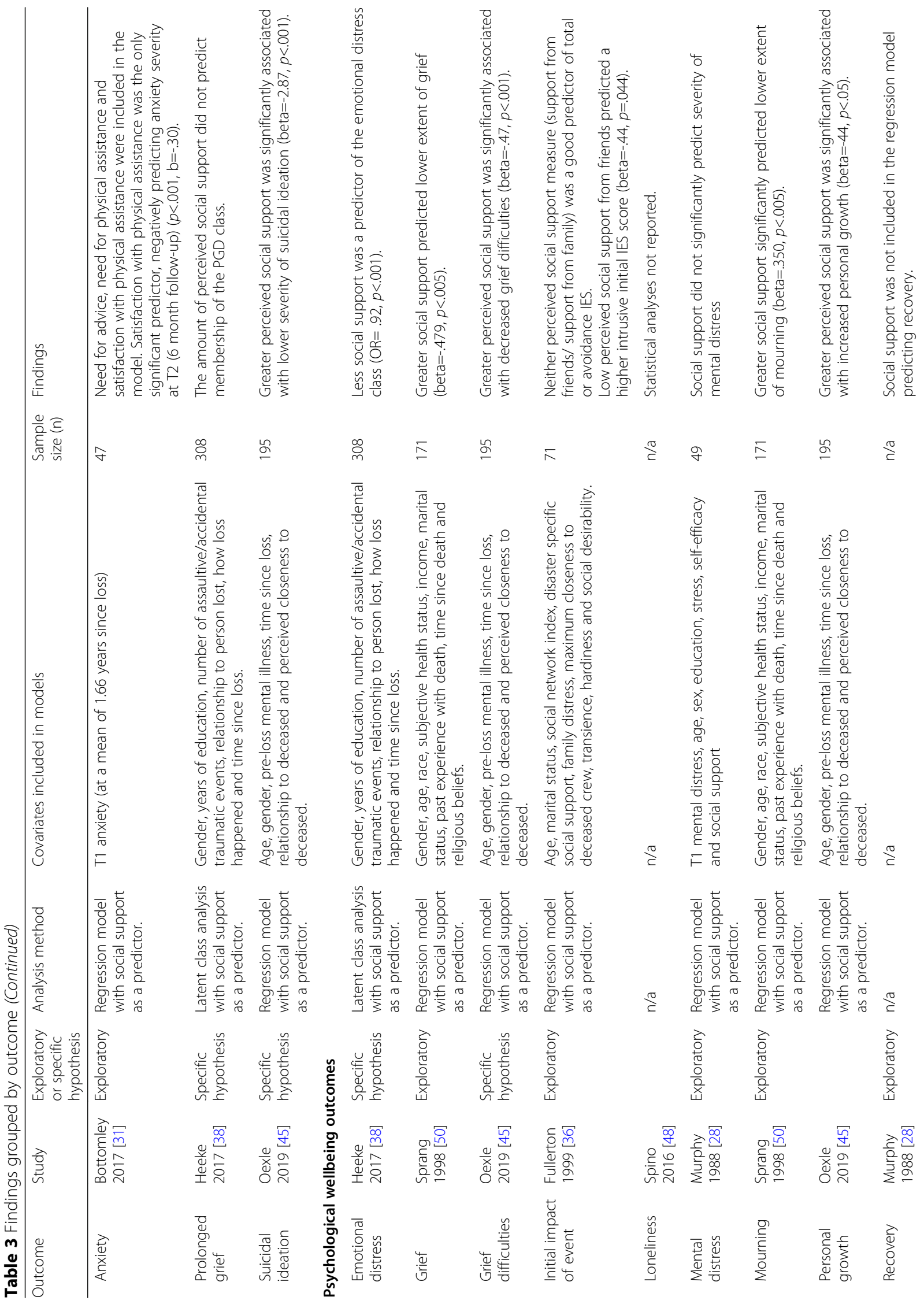




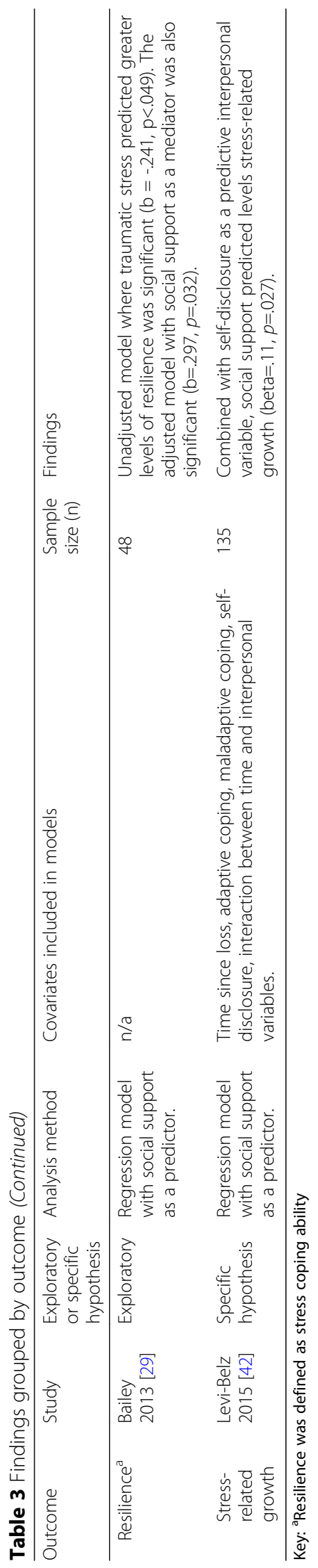




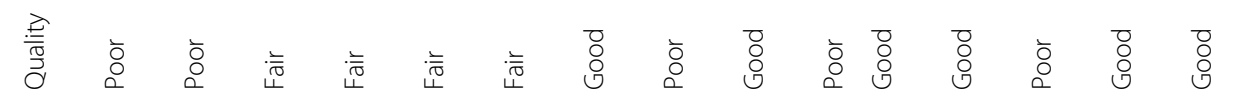

高 产

4

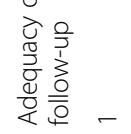

$\frac{\text { के }}{\frac{0}{5}}$

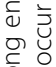

드용

월

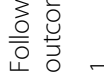

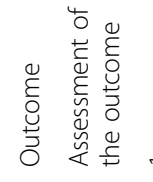

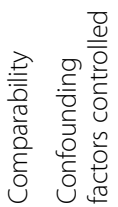

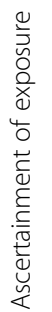

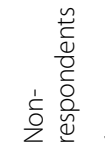<smiles>O=C=O</smiles>

$\begin{array}{llllllllllllllllll}0 & 0 & 0 & 0 & 0 & 0 & 0 & 0 & 0 & 0 & 0 & 0 & 0 & 0 & 0\end{array}$
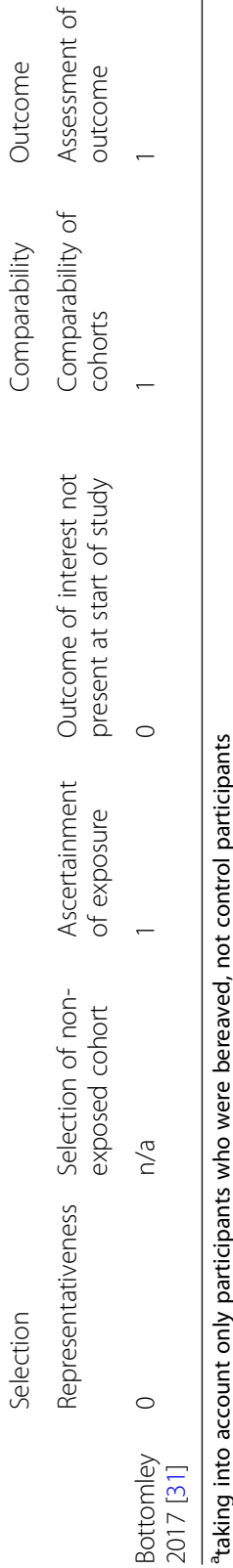
Table 5 Summary of the number of studies indicating an association between social support and each outcome

\begin{tabular}{|c|c|c|c|c|}
\hline & \multicolumn{4}{|c|}{ Number of studies indicating an association between social support and outcome } \\
\hline & Positive association $^{a}$ & Partial positive association ${ }^{b}$ & No association & Negative association \\
\hline \multicolumn{5}{|l|}{ Outcome } \\
\hline \multicolumn{5}{|l|}{ Psychiatric } \\
\hline Depression $(\mathrm{N}=7)$ & $4[27,45,47,48]$ & $2[33,36]$ & $1[31]$ & - \\
\hline $\operatorname{PTSD}(N=6)$ & $4[38,47,50,52]$ & $2[31,33]$ & - & - \\
\hline Complicated grief $(\mathrm{N}=6)$ & $2[40,43]$ & $1[33]$ & $2[44,47]$ & $1[31]$ \\
\hline Prolonged grief $(\mathrm{N}=1)$ & - & - & $1[38]$ & - \\
\hline Anxiety $(\mathrm{N}=1)$ & - & $1[31]$ & - & - \\
\hline Suicidal ideation $(N=1)$ & $1[45]$ & - & - & - \\
\hline \multicolumn{5}{|l|}{ Psychological } \\
\hline Emotional distress $(\mathrm{N}=1)$ & $1[38]$ & - & - & - \\
\hline Grief $(N=1)$ & $1[50]$ & - & - & - \\
\hline Grief difficulties $(N=1)$ & $1[45]$ & - & - & - \\
\hline Initial impact of event $(\mathrm{N}=1)$ & - & $1[36]$ & - & - \\
\hline Mental distress $(N=1)$ & - & - & $1[28]$ & - \\
\hline Mourning $(N=1)$ & $1[50]$ & - & - & - \\
\hline Personal growth $(N=1)$ & $1[45]$ & - & - & - \\
\hline Resilience $(\mathrm{N}=1)$ & $1[29]$ & - & - & - \\
\hline Stress-related growth $(\mathrm{N}=1)$ & $1[42]$ & - & - & - \\
\hline
\end{tabular}

a all measured social support variables had a significant positive association with the reduced severity of, or reduced likelihood for meeting the threshold of diagnosis for a measured outcome

${ }^{b}$ some but not all of the included social support variables had a significant positive association with reduced severity of, or reduced likelihood for meeting the threshold of diagnosis for the measured outcome, with the remaining included variables not significantly associated with the outcome

meeting the threshold for depression diagnosis or reduced depression symptom severity, with seven studies $[27,31,33,36,45,47,48]$ measuring this outcome. The single longitudinal study [31] included in this review was of fair quality and was exploratory in nature, but did control for baseline outcome measures. This study found no association between the two variables.

Four studies [27, 45, 47, 48] reported a positive association between measures of social support and depression; two were good quality $[45,47]$, one was fair quality [27] and one was poor quality [48].

Two more exploratory studies reported a partial positive association between social support and depression. A study judged as fair quality [36] found that only one (perceived support from friends) of two social support variables in one of three analysis models was crosssectionally associated with reduced symptom severity, with the other 2 models finding no association. A poor quality study [33] found that two (grief support and percentage of anticipated negative relationships) of six social support variables correlated significantly with reduced symptom severity.

PTSD (six studies) There was limited evidence that social support was associated with a reduced risk of meeting the threshold for PTSD diagnosis or with reduced symptom severity. All six studies [31, 33, 38, 47, 50, 52] that measured PTSD as an outcome found some evidence of an association between increased social support and reduced severity of/likelihood of meeting threshold for PTSD, however studies were of mixed quality.

In the longitudinal study [31], one (satisfaction with physical assistance) out of 12 measured social support variables predicted lower symptom severity. Another poor quality study [33] found a partial positive association, with only one (percentage of actual negative relationships) of out six social support variables correlated with lower symptom severity.

Four other studies [38, 47, 50, 52] found a positive association between social support and PTSD. Three of these studies were of good quality $[47,50,52]$ and one was of fair quality [38].

Complicated grief [CG] (six studies) There was mixed evidence regarding whether social support was associated with a reduced risk of meeting the threshold for CG diagnosis or reduced symptom severity, with six studies [31, 33, 40, 43, 44, 47] measuring this outcome. The included longitudinal study [31] found that only one (satisfaction with physical assistance) of 12 social support variables was associated with CG, predicting increased severity of symptoms. 
Two studies reported a positive association: two good quality studies $[40,43]$ reported a positive association between the social support risk of CG. Another study [33] found a partial positive association; this poor quality study found that two (percentage of actual negative relationships and available support system) of six social support variables was correlated with reduced symptom severity of CG.

Two more studies [44, 47], one poor quality [44] and one good quality [47], found no cross-sectional association between social support and CG.

In one fair quality cross-sectional study [38] assessed the outcome of prolonged grief, a concept similar to CG, and found no association with social support.

\section{Other psychiatric outcomes (two studies)}

The outcome of anxiety was measured in the included longitudinal study [31], where one of 12 measured social support variables at $\mathrm{T} 1$ significantly predicted lower levels of anxiety at T2 and the other variables showing no association.

A separate good quality study [45] found a significant positive association between a global social support measure and lower levels of suicidal ideation.

Other psychological wellbeing outcomes (eight studies) Nine separate psychological wellbeing outcomes were measured, demonstrating limited evidence that social support is associated with improved psychological wellbeing.

There was consistent evidence that social support influences positive wellbeing, with three separate studies [29, 42, 45] measuring personal growth, stress-related growth and resilience. A good quality study [45] found that increased personal growth was cross-sectionally associated with increased social support, and a low quality study [42] found that increased stress-related growth was cross-sectionally associated with increased social support. Social support mediated the association between traumatic stress and resilience in a poor quality study [29].

The similar constructs of grief, mourning, and extent of grief difficulties, were each significantly crosssectionally associated with social support in two separate exploratory studies $[45,50]$, both high quality.

Two studies measured distress with conflicting findings; one fair quality study [38] found a positive association between social support and emotional distress whereas another fair quality study [28] found no crosssectional association between social support and mental distress.

A single fair quality study [36] assessed the initial impact of event (IES) and found that one (perceived support from friends) of two social support variables in one of three analysis models was cross-sectionally associated with reduced impact, the other two models finding no association.

Two further psychological outcomes, loneliness [48] and recovery [28], were mentioned as having been measured in the methods sections of separate studies but were not included in statistical analysis models reported.

\section{Subgroup: people bereaved by suicide (four studies)}

Four of the cross-sectional studies reported above [42, $43,45,48]$ included only participants who had been bereaved by suicide, each controlling for a range of demographic and health-related variables. Study results consistently found that increased social support was associated with improved wellbeing.

One poor quality study [42] found a partial positive association between social support and stress-related growth, and another good quality study [43] found that social support was cross-sectionally associated with a significantly reduced risk of CG.

Two other exploratory cross-sectional studies [45, 48], one good quality [45] and one poor quality [48], demonstrated a positive association between social support and depressive symptoms, suicidal ideation and grief difficulties.

\section{Other subgroups}

No other meaningful patterns of results defined by subgroups became apparent during the process of data synthesis, whether based on type of loss or type of social support measurement. Insufficient information was provided in studies to compare results by relationship type or time since loss and the limited number of longitudinal studies did not allow for consideration of whether studies support or refute the main effects or buffering models of social support.

\section{Discussion \\ Main findings}

To the authors' knowledge, this is the first systematic review of studies describing the relationship between postloss social support and psychological wellbeing after sudden and/or violent bereavement. We found only one longitudinal study among a total of 16 identified observational studies. From these studies, we found limited yet consistent evidence that receipt of greater social support is associated with lower severity/risk of PTSD, and that social support is associated with better psychological wellbeing after bereavement by suicide. We found predominantly consistent evidence that social support is associated with lower severity of depressive symptoms/ risk of depression, but a longitudinal study found no association. We found conflicting evidence for an association between social support and CG severity/risk. For the majority of other psychiatric and psychological 
wellbeing outcomes measured in this body of literature, apart from mental distress, each was associated with social support, but for each this was only assessed in a single study.

On balance, the evidence suggests that better social support after sudden or violent bereavement is associated with better psychological wellbeing, and that this is a consistent finding among those bereaved by suicide. However, there are a number of key limitations of the current body of literature, as highlighted throughout this review, and summarised below. This suggests a need for high quality cohort studies to test this hypothesis further.

\section{Strengths and limitations of included studies}

The tendency of included studies to focus on three clinical outcomes of PTSD, depression and CG mirrors that of other reviews measuring these outcomes [60-62], generally finding these to be more common or severe among people who experience and traumatic losses as compared to other bereavements. There is clearly a need to measure other outcomes post-bereavement, including substance use, suicide attempt, and severe mental illness, as well as non-clinical outcomes such as blame, guilt and emptiness [63]. However, one explanation for this is that validated measures for psychiatric outcomes are more available than those for non-clinical constructs.

We found similar methodological weaknesses in a number of the included studies; notably the use of small sample sizes and cross-sectional designs. Studies tended to be exploratory in design and many included a range of predictive and outcome variables rather than testing a specific association. The variation in the conceptualisations of social support in the studies included in this review, and in the tools used to measure it, reflect the variety observed in social support literature more generally [7]. This demonstrates that there is a lack of clarity about how best to define and operationalise social support, which may explain some of the inconsistent results in this review. Using global measures of support rather than measuring specific aspects risks failing to capture the 'active ingredients' of social support that may benefit mental health and psychological wellbeing after bereavement.

Additionally, many studies included samples that were predominantly female, over 30 years old and, where reported, of White ethnicity. This limited demographic variability, along with low response rates and convenience sampling through peer support groups, seem to be a feature of bereavement research in general $[62,64,65]$ and limit the generalisability of results. The considerable variation in the potential confounding variables adjusted for in study models indicates inconsistency in what is thought to influence the relationship between social support and wellbeing. Key potentially confounding variables to account for in future analyses would include time [66] since bereavement, nature of relationship [67, 68] with the deceased, and pre-bereavement psychological wellbeing [69].

\section{Strengths and weaknesses of the review}

The strengths of this review are that it used a systematic approach, including a thorough search of the grey literature. The lack of additional studies found through reference list searching, citation tracking and grey literature searching increases confidence that our search strategy was comprehensive and all relevant studies were retrieved. Although the majority of the title and abstract screening was completed by one author, we use independent rating of a proportion, and agreement between both reviewing authors was high.

Whilst it would be desirable to carry out a metaanalysis to produce a combined estimated effect size from the included studies, this was not possible in this review, given the differences in measurements of social support and the range of variables that each study controlled for in their statistical analysis models.

Some potentially relevant studies had to be excluded, as additional information about categorisation of deaths was not provided by authors: inclusion of these studies may have altered our main findings. It was also not possible to ensure completely consistent categorisation for the inclusion criteria used. Deaths through illness were excluded but can be sudden in certain circumstances (e.g. death caused by a heart attack), and some of the samples recruited through support groups may have completed measures of social support with reference to their support group rather than informal support from friends and family.

Overall, generalisability is limited by the homogeneity of included samples, but cross-cultural validity is relatively good for research in this area with the inclusion of minority and non-Western populations. The inclusion of samples recruited exclusively through support organisations would limit generalisability in these studies to those who have proactively sought help, and are well enough to be involved with these organisations.

The conclusions that can be drawn from this review are limited by the lack of published longitudinal studies to clarify the temporal direction of associations. The cross-sectional studies identified do not establish whether social support improves psychological wellbeing following bereavement, or if poor psychological wellbeing following bereavement reduces actual or perceived social support through its impact on relationships with others [70]. Establishing the temporal direction of associations is critical in understanding these relationships and using this in the development of interventions based 
on informal social support. Additionally, cross-sectional studies are unable to provide empirical evidence that supports or refutes either the main effects or the buffering model of social support as measuring the rate at which wellbeing improves according to level of social support received is necessary to distinguish between the two.

\section{Implications for research and practice}

The findings of this research suggest that professionals supporting those who have been bereaved through sudden and/or violent causes, and especially those bereaved through suicide, should consider how the quantity and quality of available informal social support could be increased as a potential means to improve outcomes for their service users [20].

Priorities for research in this area should be to establish which specific types of informal support are most likely to improve psychological wellbeing, the temporal association between the degree of informal social support and a broad range of psychological wellbeing outcomes after bereavement, and the extent to which the degree of psychological morbidity influences the amount of social support available. The wider social support literature includes evidence to support a bidirectional relationship between social support and PTSD [71, 72]. Whilst general studies of support find that depression erodes social support $[6,73]$, very few studies have examined whether social support decreases the severity of depression [74]. Very little research has explored the relationship between CG and social support, most of which relates to sudden and/or violent losses, and so there is limited evidence of a relationship beyond this review. Cognitive models that explain CG highlight rumination as being a contributor to CG [75]. During the bereavement process, emotional support from others is likely to consist of opportunities to discuss the loss and its consequences, thus encouraging rumination [76]. This may explain the mixed evidence for an effect of social support on CG symptoms, as support overall is likely to improve wellbeing, but emotional support may exacerbate CG symptoms.

Given the inconsistencies in quantitative conceptualisation of the measurement of social support, qualitative research would complement this body of research by providing valuable insights to the bereavement experience in social settings. Qualitative work would also help identify the mechanisms by which some forms of informal social support may impact wellbeing after a loss.

\section{Conclusions}

This systematic review of studies describing the relationship between post-loss informal social support and psychological wellbeing after sudden and/or violent bereavement suggests that informal social support may be important in improving psychological wellbeing following violent and/or sudden bereavement. However, current evidence is of insufficient quality or quantity to permit robust conclusions. Large, longitudinal studies with demographically varied samples are required to better understand the temporal direction of the relationships between different types of informal social support and psychological wellbeing following sudden bereavement. This information is important to the development and evaluation of programmes to enhance the availability or use of specific types of informal social support for people experiencing sudden and/or violent bereavement.

\section{Supplementary information}

Supplementary information accompanies this paper at https://doi.org/10. 1186/s12888-020-02639-4

Additional file 1 Appendix 1. Search Strategy. Appendix 2. PRISMA checklist. Appendix 3. Data extraction.

\section{Abbreviations}

ASSIS: Arizona social support interview schedule; CG: Complicated grief CISS: Coppel index of social support; CSS: Crisis support scale; FSSQ: DukeUNC functional social support questionnaire; IES: Impact of event scale; ISS: Inventory of social support; MSPSS: Multidimensional scale of perceived social support; NOS: Newcastle-Ottawa Scale; NSSQ: Norbeck Social Support Questionnaire; PPI: Public and patient involvement; PSRS: Provisions of social relations scale; PSSQ: Perceived social support questionnaire; PTSD: Posttraumatic stress disorder; SSRS: Social support rating scale

\section{Acknowledgements}

We are grateful to staff in the UCL library services for assistance with the initial search strategy. We are grateful to Nina Kennedy and David Mosse, who provided PPI input to our research question and search terms.

\section{Authors' contributions}

HRS, AP and BLE and PPI representatives contributed to the design of the review; HRS developed search terms with input from AP, BLE and our PPI representatives; HRS conducted the searches; PK and HRS screened citations and critically appraised identified papers; HRS drafted the manuscript, with input from AP and BLE. All authors read and approved the final manuscript.

\section{Funding}

This work was supported by a doctoral research grant from the ESRC and the MCPin Foundation to HRS. The sponsors had no role in the study design; collection, analysis, or interpretation of the data; or the preparation and approval of the manuscript.

\section{Availability of data and materials}

All citations identified are in the public domain. The datasets used during the current study are available from the corresponding author on reasonable request.

Ethics approval and consent to participate Not applicable.

Consent for publication Not applicable.

Competing interests

The authors declare that they have no competing interests. 


\section{Author details}

'Division of Psychiatry, University College London, 6th floor, Maple House, 149 Tottenham Court Road, London W1T 7BN, UK. ²Department of Psychology, University of Roehampton, London, UK.

\section{Received: 17 October 2019 Accepted: 30 April 2020}

Published online: 29 May 2020

\section{References}

1. Stroebe M, Schut H, Stroebe W. Health outcomes of bereavement. Lancet. 2007;370:1960-73 https://doi.org/10.1016/S0140-6736(07)61816-9.

2. Schut MSH. The dual process model of coping with bereavement: rationale and description. Death Stud. 1999;23:197-224 https://doi.org/10.1080/ 074811899201046

3. Kaltman S, Bonanno GA. Trauma and bereavement: examining the impact of sudden and violent deaths. J Anxiety Disord. 2003;17:131-47 https://doi. org/10.1016/S0887-6185(02)00184-6.

4. Currier JM, Holland JM, Neimeyer RA. Sense-making, grief, and the experience of violent loss: toward a Mediational model. Death Stud. 2006; 30:403-28 https://doi.org/10.1080/07481180600614351.

5. Kristensen $P$, Weisæth $L$, Heir T. Bereavement and mental health after sudden and violent losses: a review. Psychiatry Interpers Biol Process. 2012 75:76-97 https://doi.org/10.1521/psyc.2012.75.1.76.

6. Peirce RS, Frone MR, Russell M, Cooper ML, Mudar P. A longitudinal model of social contact, social support, depression, and alcohol use. Heal Psychol Psychol. 2000;19:28-38 https://doi.org/10.1037/0278-6133.19.1.28.

7. Wang J, Lloyd-Evans B, Giacco D, Forsyth R, Nebo C, Mann F, et al. Social isolation in mental health: a conceptual and methodological review. Soc Psychiatry Psychiatr Epidemiol. 2017;52:1451-61 https://doi.org/10.1007/ s00127-017-1446-1.

8. Solomon P. Peer support/peer provided services underlying processes, benefits, and critical ingredients. Psychiatr Rehabil J. 2004;27:392-401 https://doi.org/10.2975/27.2004.392.401

9. Cohen S, Wills TA. Stress, social support, and the buffering hypothesis. Psychol Bull. 1985;98:310-57 https://doi.org/10.1037/0033-2909.98.2.310.

10. Cohen S, Underwood LG, Gottlieb BH, editors. Social support measurement and intervention: A guide for health and social scientists. New York: OxfordUniversity Press; 2000.

11. Paterson C, Robertson A, Nabi G. Exploring prostate cancer survivors' selfmanagement behaviours and examining the mechanism effect that links coping and social support to health-related quality of life, anxiety and depression: a prospective longitudinal study. Eur J Oncol Nurs. 2015;19:1208 https://doi.org/10.1016/J.EJON.2014.10.008.

12. Zhou ES, Penedo FJ, Bustillo NE, Benedict C, Rasheed M, Lechner S, et al. Longitudinal effects of social support and adaptive coping on the emotional well-being of survivors of localized prostate cancer. J Support Oncol. 2010;8:196-201 https://doi.org/10.1016/j.suponc.2010.09.004.

13. Feeney BC, Collins NL. A new look at social support. Personal Soc Psychol Rev. 2015;19:113-47 https://doi.org/10.1177/1088868314544222.

14. Vranceanu A-M, Hobfoll SE, Johnson RJ. Child multi-type maltreatment and associated depression and PTSD symptoms: the role of social support and stress. Child Abuse Negl. 2007;31:71-84 https://doi.org/10.1016/j.chiabu. 2006.04.010

15. Currier JM, Neimeyer RA, Berman JS. The effectiveness of psychotherapeutic interventions for bereaved persons: a comprehensive quantitative review. Psychol Bull. 2008:134:648-61.

16. Andriessen K, Krysinska K, Hill NTM, Reifels L, Robinson J, Reavley N, et al. Effectiveness of interventions for people bereaved through suicide: a systematic review of controlled studies of grief, psychosocial and suiciderelated outcomes. BMC Psychiatry. 2019;19:49 https://doi.org/10.1186/ s12888-019-2020-z.

17. Bartone PT, Bartone JV, Violanti JM, Gileno ZM. Peer support Services for Bereaved Survivors: a systematic review. OMEGA - J Death Dying. 2019;80: 137-66 https://doi.org/10.1177/0030222817728204.

18. Dyregrov K. Assistance from local authorities versus survivors' needs for support after suicide. Death Stud. 2002;26:647-68 https://doi.org/10.1080/ 07481180290088356

19. Wills TA. Social support and interpersonal relationships. In: Prosocial behavior. Review of personality and social psychology; 1991.
20. Logan EL, Thornton JA, Breen LJ. What determines supportive behaviors following bereavement? A systematic review and call to action. Death Stud. 2018:42:104-14 https://doi.org/10.1080/07481187.2017.1329760.

21. Stroebe W, Zech E, Stroebe MS, Abakoumkin G. Does social support help in bereavement? J Soc Clin Psychol. 2005;24:1030-50 https://doi.org/10.1521/ jscp.2005.24.7.1030.

22. Paulozzi LJ. CDC's National Violent Death Reporting System: background and methodology. Inj Prev. 2004;10:47-52 https://doi.org/10.1136/ip.2003. 003434

23. Morentin B. Sudden unexpected non-violent death between 1 and 19 years in North Spain. Arch Dis Child. 2000;82:456-61 https://doi.org/10.1136/adc. 82.6.456.

24. Moher D, Shamseer L, Clarke M, Ghersi D, Liberati A, Petticrew M, et al. Preferred reporting items for systematic review and meta-analysis protocols (PRISMA-P) 2015 statement. Syst Rev. 2015:4:1.

25. Herzog R, Álvarez-Pasquin MJ, Díaz C, Del Barrio JL, Estrada JM, Gil Á. Are healthcare workers' intentions to vaccinate related to their knowledge, beliefs and attitudes? A systematic review. BMC Public Health. 2013;13:154 https://doi.org/10.1186/1471-2458-13-154

26. Popay J, Roberts $H$, Sowden A, Petticrew M, Arai L, Rodgers M, et al. Guidance on the conduct of narrative synthesis in systematic reviews. A Prod from ESRC methods Program Version 1. 2006.

27. Cowan ME, Murphy SA. Identification of Postdisaster Bereavement Risk Predictors. Nurs Res. 1985;34:71-5 https://doi.org/10.1097/00006199198503000-00002

28. Murphy SA. Mental Distress and Recovery In a High-Risk Bereavement Sample Three Years After Untimely Death. Nurs Res. 1988;37:30-5 https:// doi.org/10.1097/00006199-198801000-00007.

29. Bailey A, Sharma M, Jubin M. The mediating role of social support, cognitive appraisal, and quality health Care in Black Mothers' stress-resilience process following loss to gun violence. Violence Vict. 2013;28:233-47 https://doi.org/ 10.1891/0886-6708.11-00151.

30. Zimet GGD, Powell SS, Farley GK, Werkman S, Berkoff KA. Psychometric Characteristics of the Multidimensional Scale of Perceived Social Support. J Pers Assess. 1990;55:610-7.

31. Bottomley JS, Burke LA, Neimeyer RA. Domains of Social Support That Predict Bereavement Distress Following Homicide Loss. Omega (United States). 2017:75:3-25 https://doi.org/10.1177/0030222815612282.

32. Barrera M, Sandler IN, Ramsay TB. Preliminary development of a scale of social support: studies on college students. Am J Community Psychol. 1981; 9(4):435-47.

33. Burke LA, Neimeyer RA, McDevitt-Murphy ME. African American homicide bereavement: aspects of social support that predict complicated grief, PTSD and depression. OMEGA - J Death Dying. 2010;61:1-24 https://doi.org/10. 2190/OM.61.1.a.

34. Hogan NS, Schmidt LA. Testing the grief to personal growth model using structural equation modeling. Death Stud. 2002;26:615-34 https://doi.org/ 10.1080/07481180290088338

35. Coppel D. The relationship of perceived social support and self-efficacy to major and minor stresses; 1980.

36. Fullerton CS, Ursano RJ, Kao T, Bharitya VR. Disaster-related bereavement: acute symptoms and subsequent depression. Aviat Sp Environ Med. 1999; 70:902-9.

37. Procidano ME, Heller K. Measures of perceived social support from friends and from family: three validation studies. Am J Community Psychol. 1983: 11(1):1-24.

38. Heeke C, Stammel N, Heinrich M, Knaevelsrud C. Conflict-related trauma and bereavement: exploring differential symptom profiles of prolonged grief and posttraumatic stress disorder. BMC Psychiatry. 2017:17:118 https:// doi.org/10.1186/s12888-017-1286-2.

39. Broadhead WE, Gehlbach SH, de Gruy FV, Kaplan BH. The Duke-UNC functional social support questionnaire. Measurement of social support in family medicine patients. Med Care. 1988;26:709-23 https://doi.org/10.1097/ 00005650-198807000-00006

40. Kristensen $P$, Weisæth $L$, Heir T. Predictors of complicated grief after a natural disaster: a population study two years after the 2004 south-east Asian tsunami. Death Stud. 2010;34:137-50 https://doi.org/10.1080/ 07481180903492455

41. Joseph S, Williams R, Yule W. Crisis support, attributional style, coping style, and post-traumatic symptoms. Pers Individ Dif. 1992;13(11):1249-51. 
42. Levi-Belz Y. Stress-related growth among suicide survivors: the role of interpersonal and cognitive factors. Arch Suicide Res. 2015;19:305-20 https://doi.org/10.1080/13811118.2014.957452.

43. Levi-Belz Y, Lev-Ari L. Is there anybody out there? Attachment style and interpersonal facilitators as protective factors against complicated grief among suicide-loss survivors. J Nerv Ment Dis. 2019;207:131-6 https://doi. org/10.1097/NMD.0000000000000940.

44. Li J, Chow AYM, Shi Z, Chan CLW. Prevalence and risk factors of complicated grief among Sichuan earthquake survivors. J Affect Disord. 2015;175:218-23 https://doi.org/10.1016/j.jad.2015.01.003.

45. Oexle N, Sheehan L. Perceived Social Support and Mental Health After Suicide Loss. Crisis. 2019:1-5 https://doi.org/10.1027/0227-5910/a000594.

46. Kliem S, Mößle T, Rehbein F, Hellmann DF, Zenger M, Brähler E. A brief form of the perceived social support questionnaire (F-SozU) was developed, validated, and standardized. J Clin Epidemiol. 2015;68:551-62 https://doi. org/10.1016/j.jclinepi.2014.11.003.

47. Rheingold AA, Williams JL. Survivors of homicide: mental health outcomes, social support, and service use among a community-based sample. Violence Vict. 2015;30:870-83 https://doi.org/10.1891/0886-6708.W-D-14-00026.

48. Spino E, Kameg KM, Cline TW, Terhorst L, Mitchell AM. Impact of social support on symptoms of depression and loneliness in survivors bereaved by suicide. Arch Psychiatr Nurs. 2016;30:602-6 https://doi.org/10.1016/j.apnu. 2016.02.001.

49. Norbeck JS, Lindsey AM, Carrieri VL. The Development of an Instrument to Measure Social Support. Nurs Res. 1981;30:264-9 https://doi.org/10.1097/ 00006199-198109000-00003.

50. Sprang G, McNeil J. Post-homicide reactions: grief, mourning and posttraumatic stress disorder following a drunk driving fatality. OMEGA - J Death Dying. 1998;37:41-58 https://doi.org/10.2190/GCGW-86DC-A30R-286A.

51. Vaux A, Phillips J, Holly L, Thomson B, Williams D, Stewart D. The social support appraisals (SS-A) scale: studies of reliability and validity. Am J Community Psychol. 1986;14(2):195-218.

52. Xu J, Wang Z, Sun Y. Indelible grief: prevalence and risk factors for posttraumatic stress disorder in Shidu parents 6 years after the Wenchuan earthquake. Curr Psychol. 2017;36:675-82 https://doi.org/10.1007/s12144016-9456-9.

53. Xiao SY. Social Support Rating Scale. Chinese Ment Heal J. 1993;7(Suppl):426.

54. Murphy SA, Chung IJ, Johnson LC. Patterns of mental distress following the violent death of a child and predictors of change over time. Res Nurs Health. 2002;25:425-37.

55. Wells G, Shea B, O'Connell D, Peterson J. The Newcastle-Ottawa scale (NOS) for assessing the quality of nonrandomised studies in meta-analyses. Ottawa Hospital Research Institute: Ottawa; 2000.

56. Elklit A, Schmidt Pedersen S, Jind L. The crisis support scale: psychometric qualities and further validation. Pers Individ Dif. 2001;31:1291-302 https:// doi.org/10.1016/S0191-8869(00)00220-8.

57. Zimet GD, Dahlem NW, Zimet SG, Farley GK. The multidimensional scale of perceived social support. J Pers Assess. 1988;52:30-41 https://doi.org/10. 1207/s15327752jpa5201_2.

58. Norbeck JS, Lindsey AM, Cahhieiu VL. Further development of the norbeck social support questionnaire: normative data and validity testing. Nurs Res. 1983;32:4-9.

59. Lakey B, Cohen S. Social support theory and measurement. In: Social Support Measurement and Intervention; 2000

60. Lobb EA, Kristjanson LJ, Aoun SM, Monterosso L, Halkett GKB, Davies A. Predictors of complicated grief: a systematic review of empirical studies. Death Stud. 2010;34:673-98 https://doi.org/10.1080/07481187.2010.496686.

61. Schnider KR, Elhai JD, Gray MJ. Coping Style Use Predicts Posttraumatic Stress and Complicated Grief Symptom Severity Among College Students Reporting a Traumatic Loss. 1997. https://doi.org/10.1037/0022-0167.54.3. 344.

62. Pitman A, Osborn D, King M, Erlangsen A. Effects of suicide bereavement on mental health and suicide risk. Lancet Psychiatry. 2014;1:86-94 https://doi. org/10.1016/S2215-0366(14)70224-X.

63. Shields C, Kavanagh M, Russo K. A qualitative systematic review of the bereavement process following suicide. OMEGA. 2017;74:426-54 https://doi. org/10.1177/0030222815612281.

64. Sveen C-A, Walby FA. Suicide survivors' mental health and grief reactions: a systematic review of controlled studies. Suicide Life-Threatening Behav. 2008:38:13-29 https://doi.org/10.1521/suli.2008.38.1.13.
65. Linde K, Treml J, Steinig J, Nagl M, Kersting A. Grief interventions for people bereaved by suicide: a systematic review. PLoS One. 2017;12:e0179496 https://doi.org/10.1371/journal.pone.0179496.

66. Feigelman W, Jordan JR, Gorman BS. How they died, time since loss, and bereavement outcomes. OMEGA. 2009;58:251-73 https://doi.org/10.2190/ OM.58.4.a.

67. Pitman AL, Osborn DPJ, Rantell K, King MB. Bereavement by suicide as a risk factor for suicide attempt: a cross-sectional national UK-wide study of 3432 young bereaved adults. BMJ Open. 2016;6:e009948 https://doi.org/10.1136/ bmjopen-2015-009948.

68. Tidemalm D, Runeson B, Waern M, Frisell T, Carlström E, Lichtenstein P, et al Familial clustering of suicide risk: a total population study of 11.4 million individuals. Psychol Med. 2011;41:2527-34 https://doi.org/10.1017/ S0033291711000833

69. Bolton JM, Au W, Leslie WD, Martens PJ, Enns MW, Roos LL, et al. Parents bereaved by offspring suicide. JAMA Psychiatry. 2013;70:158 https://doi.org/ 10.1001/jamapsychiatry.2013.275.

70. Hannays-King C, Bailey A, Akhtar M. Social support and black mothers' bereavement experience of losing a child to gun homicide. Bereave Care. 2015;34:10-6 https://doi.org/10.1080/02682621.2015.1028199.

71. Ozer EJ, Best SR, Lipsey TL, Weiss DS. Predictors of posttraumatic stress disorder and symptoms in adults: a meta-analysis. Psychol Bull. 2003;129:5273 https://doi.org/10.1037/0033-2909.129.1.52.

72. Laffaye C, Cavella S, Drescher K, Rosen C. Relationships among PTSD symptoms, social support, and support source in veterans with chronic PTSD. J Trauma Stress. 2008;21:394-401 https://doi.org/10.1002/jts.20348.

73. Stice E, Ragan J, Randall P. Prospective relations between social support and depression: differential direction of effects for parent and peer support? J Abnorm Psychol. 2004;113:155-9 https://doi.org/10.1037/0021-843X.113.1. 155.

74. Wade TD, Kendler KS. The relationship between social support and major depression. J Nerv Ment Dis. 2000;188:251-8 https://doi.org/10.1097/ 00005053-200005000-00001.

75. Eisma MC, Stroebe MS, Schut HAW, Stroebe W, Boelen PA, van den Bout J. Avoidance processes mediate the relationship between rumination and symptoms of complicated grief and depression following loss. J Abnorm Psychol. 2013;122:961-70 https://doi.org/10.1037/a0034051.

76. Rose AJ, Carlson W, Waller EM. Prospective associations of co-rumination with friendship and emotional adjustment: considering the socioemotional trade-offs of co-rumination. Dev Psychol. 2007;43:1019-31 https://doi.org/10 1037/0012-1649.43.4.1019.

\section{Publisher's Note}

Springer Nature remains neutral with regard to jurisdictional claims in published maps and institutional affiliations.
Ready to submit your research? Choose BMC and benefit from:

- fast, convenient online submission

- thorough peer review by experienced researchers in your field

- rapid publication on acceptance

- support for research data, including large and complex data types

- gold Open Access which fosters wider collaboration and increased citations

- maximum visibility for your research: over $100 \mathrm{M}$ website views per year

At BMC, research is always in progress.

Learn more biomedcentral.com/submissions 